\title{
Effect of Bag Location along a Suspension Line on Nylon Bag Digestibility Estimates in Bison and Cattle
}

\section{A.W.L. HAWLEY}

Erwin and Elliston(1959), Van Dyne (1962), and Quinton (1972) reported that the relative positions of nylon bags suspended within the rumen did not significantly affect the digestibilities of forages within the bags. However, digestive capacity varies spatially within the rumen (Balch and Johnson 1950; Miles 1951) and the location of samples within the rumen sometimes affects digestibility estimates (Tomlin et al. 1967). If the nylon bag technique is used in animals fitted with small-diameter cannulae, insertion and removal of the bags is facilitated by arranging the bags in a line (e.g. Van Dyne 1962). The mixing of individual bags with digesta, and hence digestibility estimates, may vary along the line. This experiment was conducted in conjunction with other nylon bag experiments (Hawley et al. 1980) to determine the effect of the location of nylon bags along the suspension line on nylon bag digestibility estimates in bison and cattle.

\section{Methods}

Nylon bags containing $2 \mathrm{~g}$ of finely ground sedge (Carex atherodes) were fastened along nylon lines as described by Hawley et al. (1980). A line of 20 bags was incubated in the rumen of each of one bison receiving hay and one bison receiving hay plus a grain supplement. A line of 15 bags was tested in each of one Hereford receiving hay and one Hereford receiving hay plus the supplement. Twenty to $25 \mathrm{~cm}$ of line separated the first bag on each line from the rumen cannula. The distal end of the line was weighted with approximately $120 \mathrm{~g}$ of brass ball bearings in nylon bags. Dry matter disappearance (DMD) after $48 \mathrm{~h}$ intraruminal incubation was the estimate of forage digestibility. The effect of location on the string on DMD was evaluated using linear regression. Other statistical analyses were as described by Hawley et al. (1980).

\section{Results and Discussion}

Sample DMD varied with the location of bags on the suspension line (Fig. 1). Correlation coefficients for regressions of DMD on distance from the end of the line were significant for cattle but not for bison (Table 1). There were no differences $(P>0.05)$ among the regression coefficients. The effect of bag location on DMD in cattle involved a reduction of 6 to 10 percentage units from the free end to the cannula end of the line. The decrease in DMD in cattle as the bags were located closer to the cannula can be attributed to the stratification of digesta resulting in a greater digestive capacity in the ventral than in the dorsal rumen (Balch and Johnson 1950; Miles 1951). The slopes of the bison regressions were also negative but were insignificant. The DMD values in bison indicated that the effect of bag position on DMD in bison was not always regular. The animal species and ration effects on DMD (Table 1) were

\footnotetext{
The author's address is Alberta Environmental Centre, Bag 4000, Vegreville, Alberta, TOB 4L.

The author thanks H.W. Reynolds, Canadian Wildlife Service, Edmonton, Alberta, for his valuable comments on the manuscript and R.J. Hudson, Department of Animal Science, University of Alberta, Edmont on, for providing funds for computer time.

Manuscript received October, 1, 1979.
}
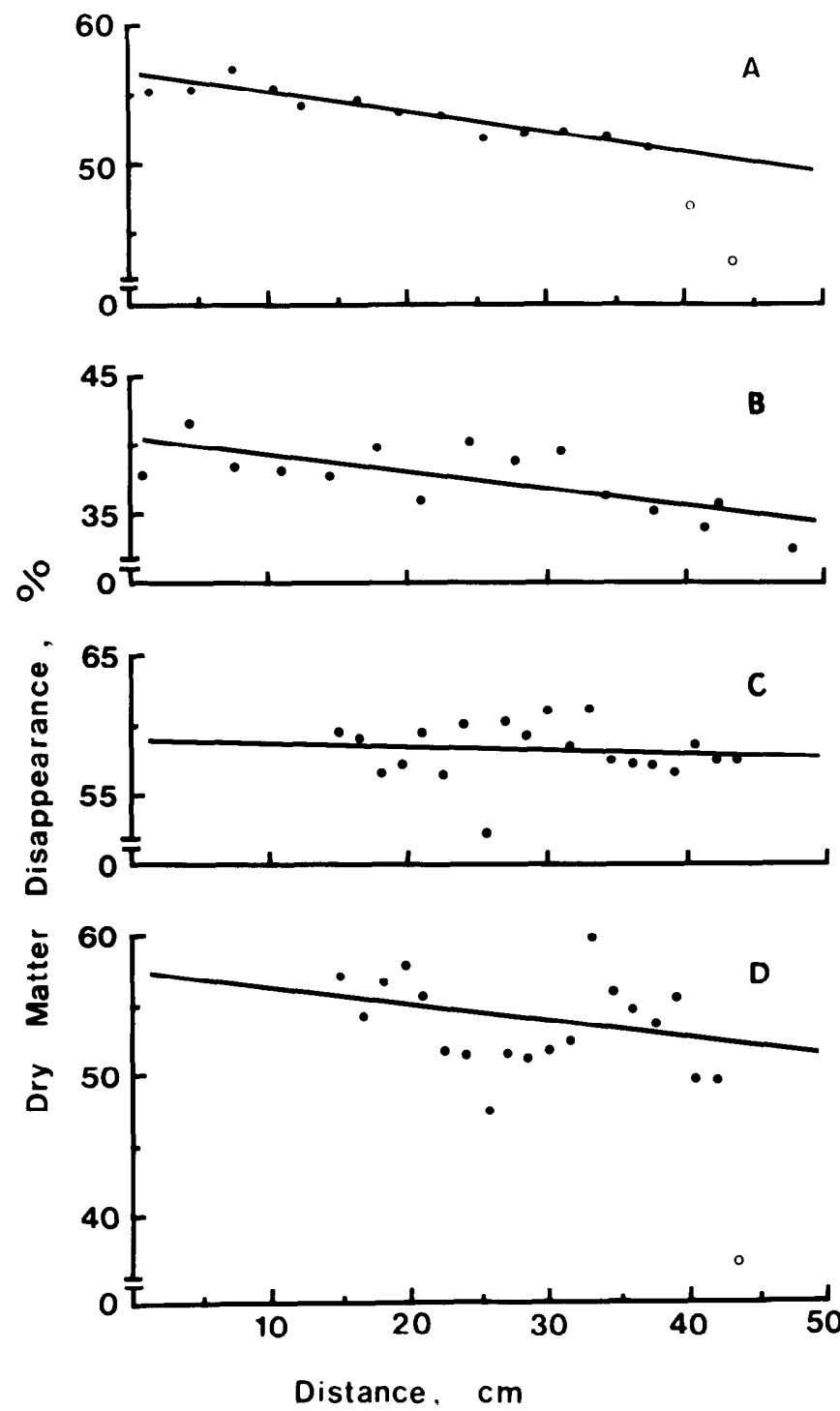

Fig. 1. Nylon bag dry matter disappearance at different distances from the free end of a suspension line in cattle receiving hay $(A)$ or hay plus a grain supplement $(B)$ and bison receiving hay $(C)$ or hay plus supplement $(D)$. Open dots represent points excluded from statistical analyses.

similar to those described by Hawley et al. (1980).

Variabilities about the DMD means of bags incubated simultaneously in the same rumen (Table 1) were greater in this study than those reported by Quinton (1972) and Tomlin et al. (1967) who also attached nylon bags to lines but perhaps over shorter distances. Van Dyne (1962) observed an average absolute differ- 
Table 1. Means and standard deviations (SD) for dry matter disappearance (DMD) and regression equations describing the effect of distance in $\mathrm{cm}$ (x) of samples from the free end of the suspension line on DMD.

\begin{tabular}{|c|c|c|c|c|}
\hline \multirow[b]{2}{*}{ Species } & \multirow[b]{2}{*}{ Ration } & $\mathrm{DMD}, \%$ & \multirow[b]{2}{*}{ Regression equation } & \multirow[b]{2}{*}{ Correlation coefficient } \\
\hline & & Mean $\quad \mathrm{SD}$ & & \\
\hline \multirow{2}{*}{ Bison } & hay & $58 \mathrm{a}^{1} \pm 2.1$ & $\mathrm{DMD}=-0.02 \mathrm{x}+58.92 .1$ & 0.1 \\
\hline & hay + supplement & $54 \mathrm{~b} \pm 3.3$ & $\mathrm{DMD}=-0.12 \mathrm{x}+57.53 .2$ & 0.3 \\
\hline \multirow{2}{*}{ Cattle } & hay & $54 b \pm 1.7$ & $\mathrm{DMD}=-0.14 \mathrm{x}+56.50 .7$ & $0.9 * * 3$ \\
\hline & hay + supplement & $37 \mathrm{c} \pm 2.5$ & $\mathrm{DMD}=0.12 \mathrm{x}+40.41 .9$ & $0.7^{*}$ \\
\hline
\end{tabular}

'Means followed by different letters were significantly different $(P<0.05)$.

${ }^{2} \mathrm{Standard}$ error of estimate.

${ }^{*} P<0.002 ;{ }^{* *} P<0.0001$

ence of $5 \%$ between duplicate bags on a line. The average absolute difference between adjacent bags in the present experiment was 2 percentage units.

When the lines of bags were removed from the rumens in the present experiment, the weighted end of the line appeared to be at the bottom of the rumen. This was not always the case in other experiments using the same suspension method (Hawley, unpublished results). Circulation of bags within the rumen may counteract a position effect and reduce variability in DMD. Rodriguez (1968) found that variability was increased both by weighting the suspension line and by shortening the length of the line. Mehrez and Ørskov (1977) believed that $25 \mathrm{~cm}$ of line was sufficient to allow free movement of bags in the rumens of sheep. Rumen size, height of the fistula, and level of gut fill will affect the length of line needed to ensure continuous immersion of bags in digesta. The excessive reduction in DMD of samples located closest to the rumen cannula in cattle receiving hay (Fig. $1 \mathrm{~A}$ ) and bison receiving the supplement (Fig. 1D) can be attributed to the location of these bags near the top of the rumen contents. Twenty-five $\mathrm{cm}$ of free line was insufficient to allow thorough and uniform mixing of bags in rumen contents in adult bison and cattle.

Using other suspension methods, such as fastening bags to a heavy bar, bag position has been observed to have no significant effect on DMD (Erwin and Elliston 1959; Peden et al. 1974; Van Keuren and Heinemann 1962). If bags are attached in a row along a line, the location of bags along the line is a source of variation which should not be ignored. More than $25 \mathrm{~cm}$ of free line should be allowed between the cannula and the most proximal bag when bags are incubated in the rumens of large animals such as cattle. Bags should be suspended so as to ensure that they remain in close proximity to each other. Neathery (1969) described a method in which bags were fastened along a piece of tygon tubing and the ends of the tubing were joined after the tubing and bags were inserted into the rumen. If such a loop of bags was suspended by over $25 \mathrm{~cm}$ of line, the method would maintain the bags in close proximity to one another once in the rumen, allow the bags to mix thoroughly with rumen contents, prevent entanglement of bags, and allow easy insertion and removal of bags through small cannulae.

\section{Literature Cited}

Balch, C.C., and V.W. Johnson. 1950. Factors affecting the utilization of food by dairy cows. 2. Factors influencing the rate of breakdown of cellulose (cotton thread) in the rumen of the cow. Brit. J. Nutr. 4:389-395.

Erwin, E.S., and N.G. Elliston. 1959. Rapid method of determining digestibility of concentrates and roughages in cattle. J. Anim. Sci. 18:1518 (Abstr.).

Hawley, A.W.L., D.G. Peden, H.W. Reynolds, and W.R. Stricklin. 1980. Bison and cattle digestion of forages from the Slave River lowlands, Northwest Territories, Canada. J. Range Manage. (In Press.)

Mehrez, A.Z., and E.R. N. 1977. A study of the artificial fibre bag technique for determining the digestibility of feeds in the rumen. J. Agr. Sci. 88:645-650.

Miles, J.T. 1951. Rumen digestion of some crude fibre constituents. J. Dairy Sci. 34:492 (Abstr.).

Neathery, M.W. 1969. Dry matter disappearance of roughages in nylon bags suspended in the rumen. J. Dairy Sci. 52:74-78.

Peden, D.G., G.M. Van Dyne, R.W. Rice, and R.M. Hansen. 1974. The trophic ecology of Bison bison L. on shortgrass plains. J. Appl. Ecol. 11:489-498.

Quinton, D.A. 1972. Standardization of the nylon bag technique and its use in the nutritive evaluations of northestern Colorado range sites. Ph.D. Thesis, Colorado State Univ., Fort Collins, $130 \mathrm{p}$.

Rodriguez, H. 1968. In vivo bag digestibility: the relative position within the rumen. Rev. Cubana Cienca Agric. (Eng. ed.) 2:285-287.

Tomlin, D.C., M.J. Anderson, and L.E. Harris. 1967. Refinements in the in vivo bag rumen technique. Proc. West. Sec. Amer. Soc. Anim. Sci. 18:291-296.

Van Dyne, G.M. 1962. Micro-methods for nutritive evaluation of range forages. J. Range Manage. 15:303-314.

Van Keuren, R.W., and W.W. Heinemann. 1962. Study of a nylon bag technique for in vivo estimation of forage digestibility. J. Anim. Sci. $21: 340-345$ 